FUSION OF NOTOCHORD TO NEURAT TUBE IN A HUMAN EMBRYO OF THE SIXTH WEEK

\author{
BRADLEY M. PATTEN \\ University of Michigan Medical School, Ann Arbor \\ ONE PLATE (THREE FIGURES)
}

There is a very proper reluctance about publishing papers based upon single instances of abnormal development. Fmbryological malformations are far from simple phenomena, and one naturally attempts to find a number of cases to form the basis of a report, since only a group of related defects, or a series of individuals showing different stages in the genesis of a given defect, are likely to help much in understanding the processes involved. Consequently, when an embryo showing a local fusion of the notochord with the developing spinal cord came into our Michigan collection, it was not reported for several years in the hope that other such cases might be encountered. Fusions of the notochord at its cephalic end with Rathke's pocket or with pharyngeal epithelium are not uncommon occurrences. Fusion with the neural tube at cord levels is apparently most unusual. No embryo with this condition has been seen in the interval, nor has a search of the literature brought to light any published description of such a case. When, finally, questioning of a group of embryologists of wide experience revealed that none of them had seen any case of the type, it seemed desirable to publish photographs of the condition. If such a fusion of the notochord with the neural tube is unique, it should be on record; if, as is more probable, similar cases have been seen but not reported, the reporting of this case may bring them out of seclusion, and lead toward the accumulation of sufficient data for intensive study. 
The embryo in question was sent in to this laboratory without any accompanying data. The specimen, measuring $11.2 \mathrm{~mm}$ in crown-rump length, had obviously been promptly fixed and appeared to be in excellent condition so it was catalogued (FH 268) and designated for serial sectioning. As luck would have it, we already had good transverse series in this age range, so this embryo was cut sagittally, which proved to be the ideal orientation to show the notochordal fusion to best adrantage. Plate 1, A, shows, for general orientation, an entire section from near the middle of the series. The rectangle indicates the location of the moderately magnified photomicrocraph appearing as $B$ in the same plate. This photograph shows, between the mesenchrmal clusters constituting the primordia of the centra of the seventh cervical and the first thoracic vertebrae, an abrupt deviation of the notochord. Here the notochord executes a $\mathrm{C}^{-}$-shaped bend dorsad, to meet and fuse with the neural tube. At the point of fusion the floor plate of the neural tube is pulled toward the notochord. The entire picture suggests the two structures had fused at a considerably younger stage when they lay close together, and that the persistence of this fusion as the two structures became separated pulled both of them out of their normal alignment. The high power photomicrograph (C) shows, at the point of mion, closely packed notochordal cells adherent to the marsinal layer of the spinal cord. The connection involves four $10 \mu$ sections.

As to the time and place of the origin of this condition, one can perhaps formulate a reasonable hypothesis. Allowing: for the four occipital somites, the interspace between the seventh cervical and the first thoracic vertebra, where the adhesion appears, is opposite the eleventh somite. It seems probable that the adhesion was formed at about the 10- or 11 somite stage when the cells destined to form the floo" of the neural tube and the cells giving rise to the notochord were juxtaposed in the growth center just cephalic to the primitive streak. Judging from the rery small extent of the adherence, whatever induced it must have been operative for only a few 
hours since at this age pairs of somites are being cut off at the rate of two to three a day, and this defect is well within the level of a single pair of somites. With the growth and differentiation which has intervened since its formation, the area of adhesion has come to lie relatively much farther cephalad in the body and the portion of the notochord subsequently formed appears entirely normal in its configuration and relations.

It is very difficult to guess just what the resultant abnormalities at later stages would have been had this embryo been permitted to continue its development. One can surmise that the intervertebral disc might have been weakened and prone to rupture where it developed around the misplaced notochord. It is conceivable that the aberrant notochordal tissue might have become involved in the formation of some sort of a tumor-like mass or cyst. The disturbance of the marginal layer of the cord scarcely seems sufficient to interfere with the derelopment of the funiculi adjacent to the ventral suleus, although this would have to be considered as a possibility. Beyond such rather futile speculations one cannot go in the absence of evidence such as would be furnished by other embryos showing similar conditions at different ages. 


\section{PLATE 1}

EXPLANATION OF FIGURES

A Photomicrograph of entire section near middle of series with rectangle indicating the area shown more lighly magnified in $\mathrm{B}$.

B Photomicrograph at moderate magnification to show the topography in the neighborhood of the adhesion. The rectangle indieates the area shown in $C$ in ligher magnification.

G Plotomicrograph $(\times 200)$ showing the details in the area of fusion. 

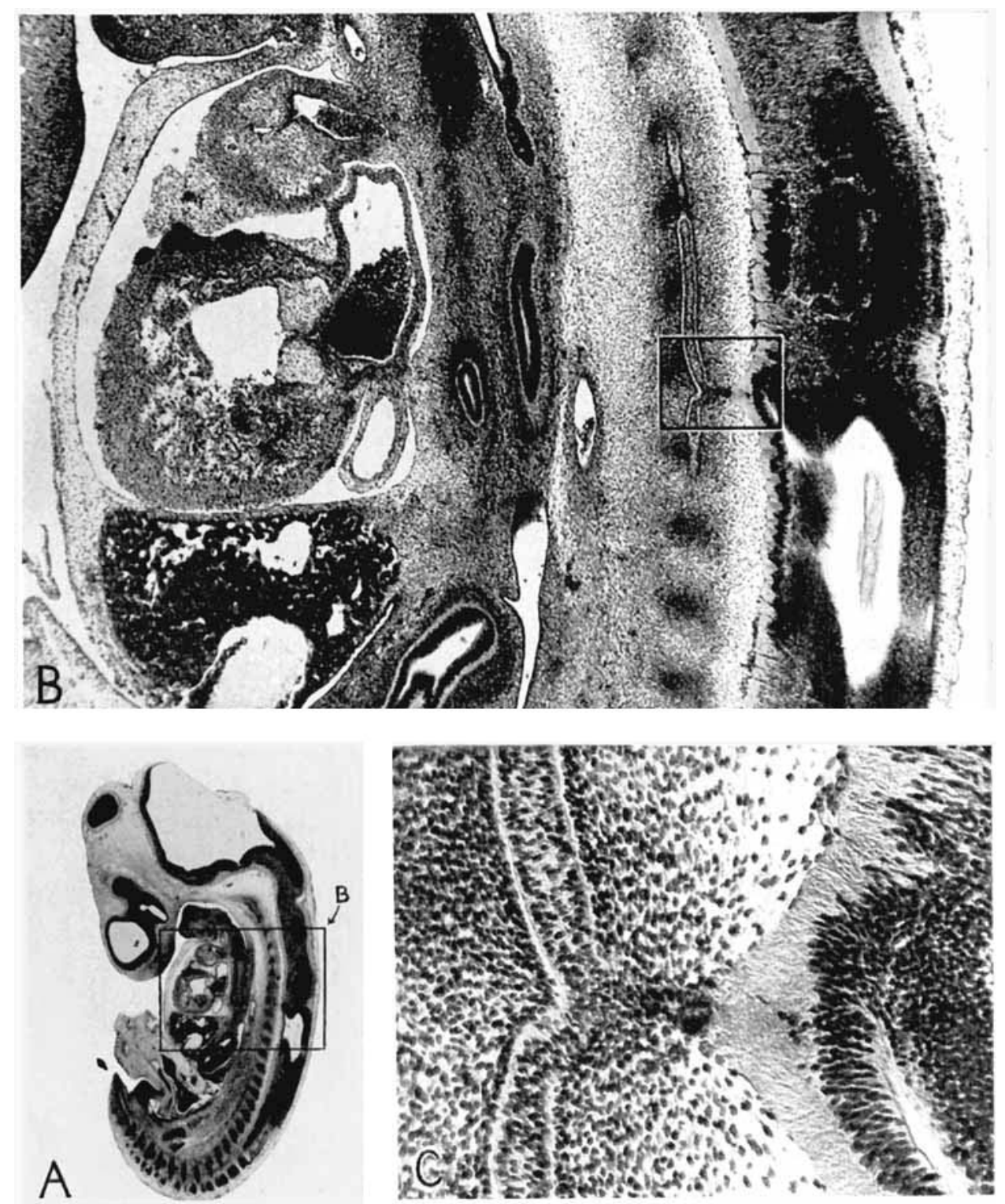